
Research Square
Preprints are preliminary reports that have not undergone peer review.
They should not be considered conclusive, used to inform clinical practice, or referenced by the media as validated information.

\title{
Bilateral Synchronous 3-port Transperitoneal Laparoscopic Ureterolithotomy: A Case Report
}

Bharath N Kumar ( $\nabla$ drbharathkumarn@gmail.com )

Command Hospital Southern Command Pune https://orcid.org/0000-0002-9231-9785

\section{Research Article}

Keywords: Bilateral large ureteric calculi, minimally invasive surgery, transperitoneal laparoscopic ureterolithotomy, bilateral synchronous laparoscopic urologic surgery, case report

Posted Date: November 9th, 2021

DOI: https://doi.org/10.21203/rs.3.rs-756069/v1

License: (9) This work is licensed under a Creative Commons Attribution 4.0 International License. Read Full License 


\section{Abstract}

Transperitoneal laparoscopic ureterolithotomy is a well-established minimally invasive procedure for management of large impacted ureteric stones since the last 3 decades. We present a case of a 51 years old gentleman, who presented with bilateral large upper ureteric calculi with obstructive uropathy and azotemia, managed successfully with bilateral synchronous 3-port transperitoneal laparoscopic ureterolithotomy, and to our knowledge is the first such case to be reported in literature.

\section{Introduction}

Transperitoneal laparoscopic ureterolithotomy (TLUL) is presently one of the well-established minimally invasive surgeries for large impacted ureteric stones. However, there has been no case of bilateral synchronous 3-port TLUL reported till now. We report one such uniquely managed case during the coronavirus pandemic.

\section{Case Presentation}

51 years old gentleman, presented with right flank pain of 2 months' duration in Oct 2020 to our tertiary care hospital. On admission, his serum creatinine was $9.73 \mathrm{mg} / \mathrm{dl}$ and blood urea was $180 \mathrm{mg} / \mathrm{dl}$. Patient had hypertension on admission which was managed with anti-hypertensives. Non-contrast computerized tomography (NCCT) scan of abdomen revealed B/L large proximal ureteric calculi (right proximal ureteric calculus measuring $2 \mathrm{~cm}$ and left proximal ureteric calculus measuring $2.96 \mathrm{~cm}$ ) causing B/L gross hydroureteronephrosis and severe cortical thinning (Fig. 1).

He underwent B/L percutaneous nephrostomy (PCN) (Fig. 2). Later serum creatinine settled to $3 \mathrm{mg} / \mathrm{dl}$, after being on B/L PCN for about 20 days. Right and Left PCN urine outputs were 1-1.5 litres/day \& 2-2.5 litres/day respectively. Patient was planned for synchronous $B / L$ transperitoneal laparoscopic ureterolithotomy (TLUL) along with $B / L$ antegrade double " $J$ " (DJ) stenting under general anaesthesia. Initially patient was placed under modified right lateral decubitus position and pneumoperitoneum was created through Verres needle technique; 3 ports were placed - one $10 \mathrm{~mm}$ camera port just above the umbilicus, one $10 \mathrm{~mm}$ working port in the midline suprapubic region and one $5 \mathrm{~mm}$ working port in the midline epigastric region (Fig. 3a). He underwent left TLUL and antegrade DJ stenting. Later he was placed in left modified lateral decubitus position and underwent right TLUL and antegrade DJ stenting using the same 3 ports. Both the left and right ureteric calculi were removed through the $10 \mathrm{~mm}$ suprapubic port and a tube drain was placed through the same port site (Fig. $3 \mathrm{~b}$ and $3 \mathrm{c}$ ). Total duration of the surgery was only 150 mins including the time taken for changing the patient's position and there was no significant blood loss. Bilateral PCN catheters were removed on first postoperative day (POD) after confirming the satisfactory position of B/L DJ stents (Fig. 4). Drain was removed on second POD and he was discharged after removal of perurethral catheter on third POD. Bilateral DJ Stents were removed 1 month later and his serum creatinine had settled to $1.5 \mathrm{mg} / \mathrm{dl}$ then. His postoperative NCCT scan showed improvement of hydronephrosis of both the kidneys (Fig. 5). 


\section{Discussion And Conclusions}

TLUL was first described by Raboy et al for a $14 \mathrm{~mm}$ distal ureteric cysteine calculus which was not amenable to ureteroscopic laser lithotripsy [1]. Retroperitoneal LUL gained popularity when Gaur et al described their technique of hydraulic balloon dilation that provided quick access to the retroperitoneum [2]. LUL with both transperitoneal and retroperitoneal techniques have been used for large impacted ureteric calculi, with stone size more than $15 \mathrm{~mm}$ and it has been found that both approaches are effective. The transperitoneal technique has significantly shorter operative time and lower rate of open conversion but has a significantly longer time to oral intake [3].

In a case series of synchronous bilateral transperitoneal laparoscopic surgery for renal and ureteric stones, 3 patients underwent B/L laparoscopic pyelolithotomy and a 11-year-old boy underwent right pyelolithotomy for renal pelvis stone and left ureterolithotomy for left upper ureteric calculus; 4 ports were used in these patients [4]. Linhui et a/ have reported 2 cases of bilateral transumbilical laparoscopic single-site (LESS) surgeries in a single operative session. One patient underwent right ureterolithotomy and left varicocelectomy. The other patient underwent right simple nephrectomy for nonfunctioning kidney due to ureteric calculus and left ureterolithotomy; the total operative time was 340 minutes (120 min and 220 min, respectively) [5].

But till date, no case of B/L synchronous 3-port TLUL similar to ours has been reported in the literature. The decision to do such a procedure was taken considering the large size of the bilateral ureteric stones, both the kidneys showing adequate function in terms of adequate urine output and also the thin built of the patient which allowed successful completion of the surgery with only use of 3 midline ports. Also if the patient had undergone a metachronous surgery, he would have had to remain with the contralateral PCN for a longer duration affecting his quality of life and the surgeon would have had to deal with intraperitoneal adhesions during the second surgery. Moreover, the requirement to avoid additional operative slots, repeat admission and general anaesthesia to the patient during the difficult times of the coronavirus pandemic, lead the surgeon to think about this innovative idea of $B / L$ synchronous 3-port TLUL, thus providing the patient the maximum benefit of minimally invasive surgery.

\section{Declarations}

Funding - None

Conflicts of interest/Competing interests - None

Ethics approval - It is a case report and ethics approval is not applicable

Consent to participate - Taken

Consent for publication - Taken

Availability of data and material - Original data and material 
Code availability (software application or custom code) - Not applicable

Authors' contributions - Single author study, responsible for all relevant contributions

\section{References}

1. Raboy A, Ferzli GS, loffreda R, et al. Laparoscopic ureterolithotomy. Urology. 1992;39:223-5.

2. Gaur DD, Agarwal DK, Purohit KC, Darshane AS, Shah BC. Retroperitoneal laparoscopic ureterolithotomy for multiple upper midureteral calculi. J Urol. 1994;151:1001-2.

3. Khalil M, Omar R, Abdel-Baky S, Mohey A, Sebaey A. Laparoscopic ureterolithotomy; which is better: Transperitoneal or retroperitoneal approach? Turk J Urol. 2015;41(4):185-190.

4. Nouralizadeh A, Kashi AH, Valipour R, Nasiri Kopaee MR, Zeinali M, Sarhangnejad R. Bilateral Laparoscopic Stone Surgery for Renal Stones- A Case Series. Urol J. 2017;14(6):5043-5046.

5. Linhui W, Zhenjie W, Bing L et al. Synchronous bilateral laparoendoscopic single-site urological surgeries via the umbilicus: a report of 2 cases. Journal of Medical Colleges of PLA. 2011;26(6):345352.

\section{Figures}




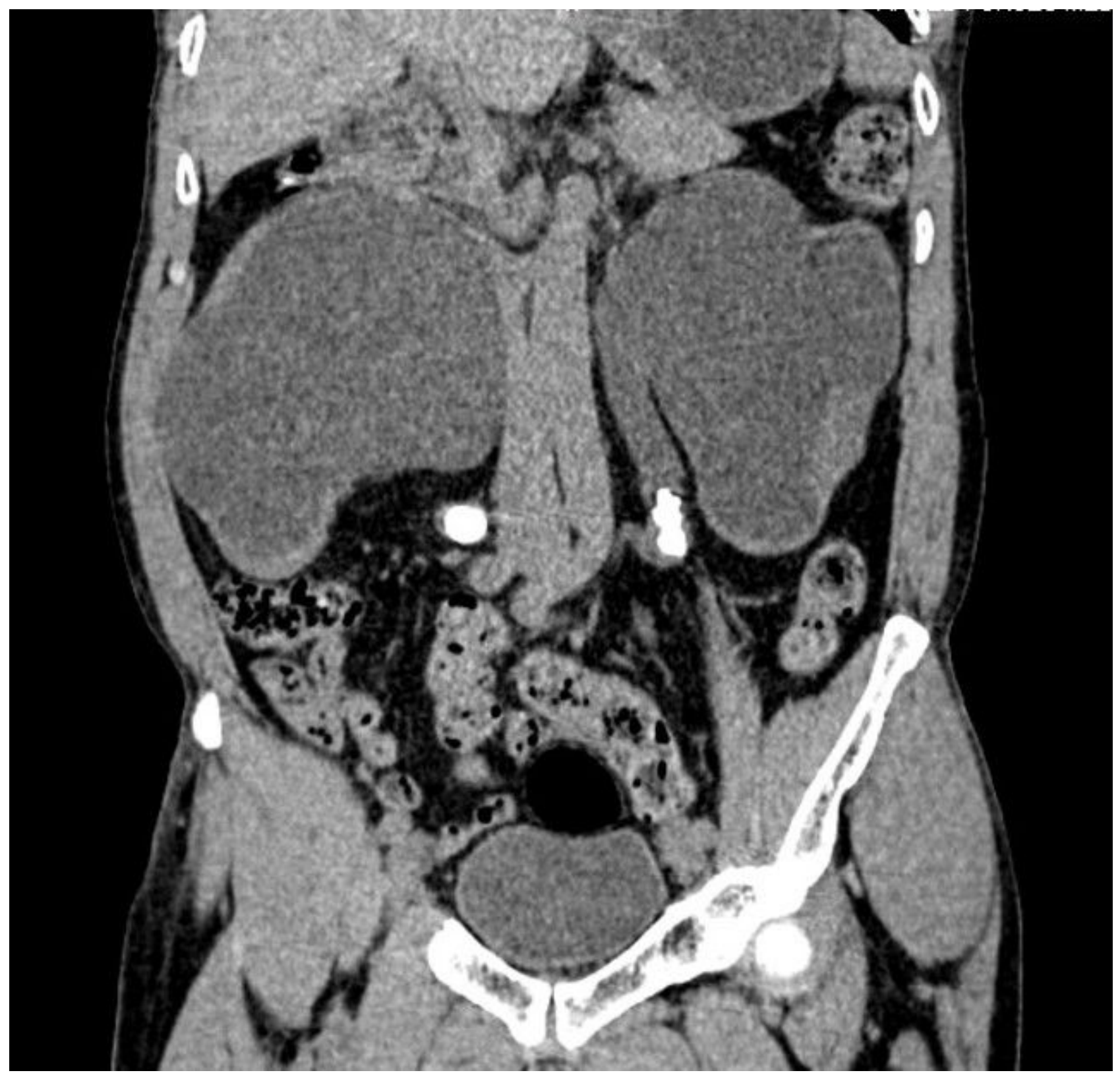

Figure 1

NCCT KUB Scan showing bilateral large upper ureteric calculi with gross hydroureteronephrosis and cortical thinning 


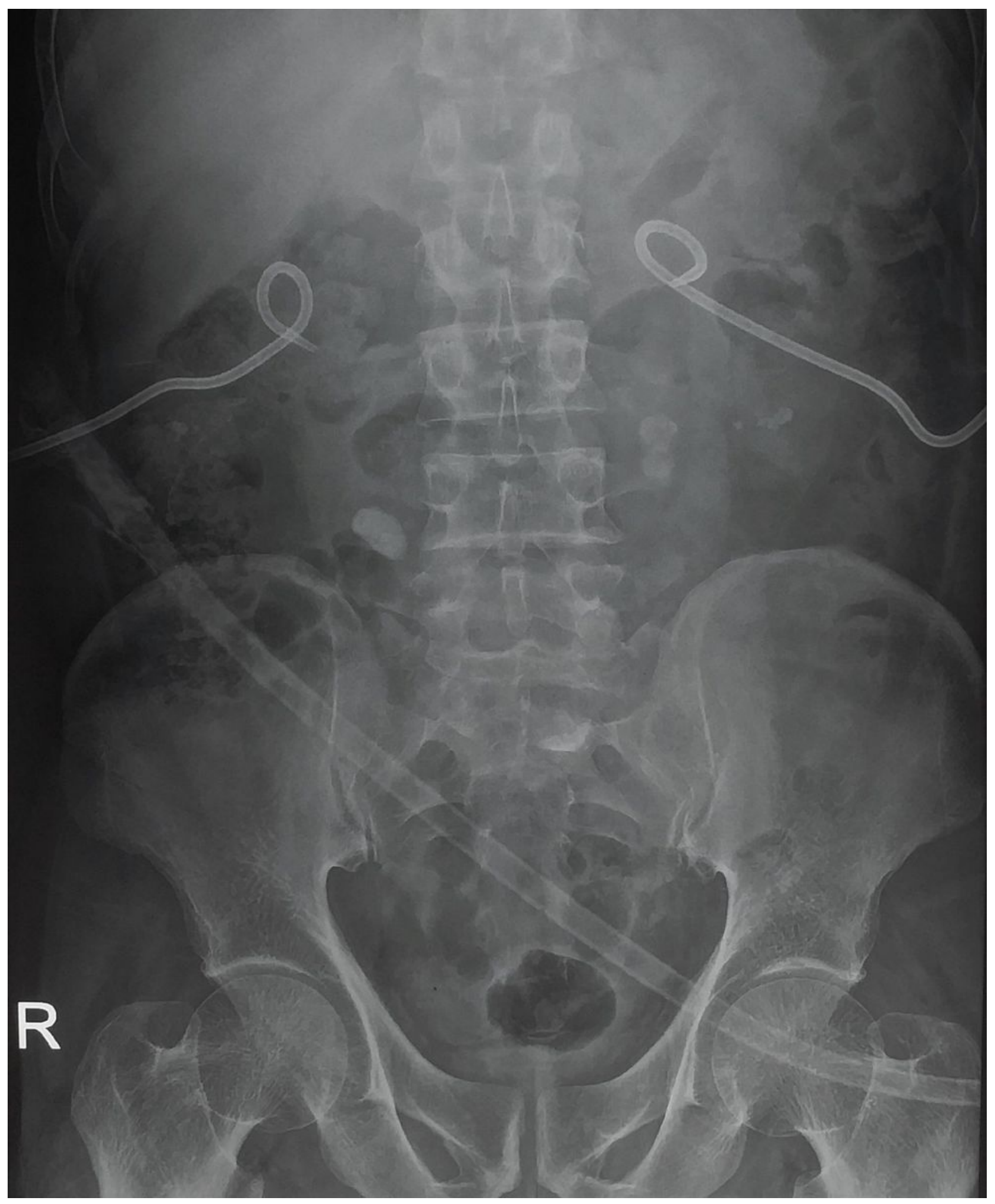

Figure 2

X-ray KUB showing bilateral ureteric calculi with bilateral percutaneous nephrostomy 

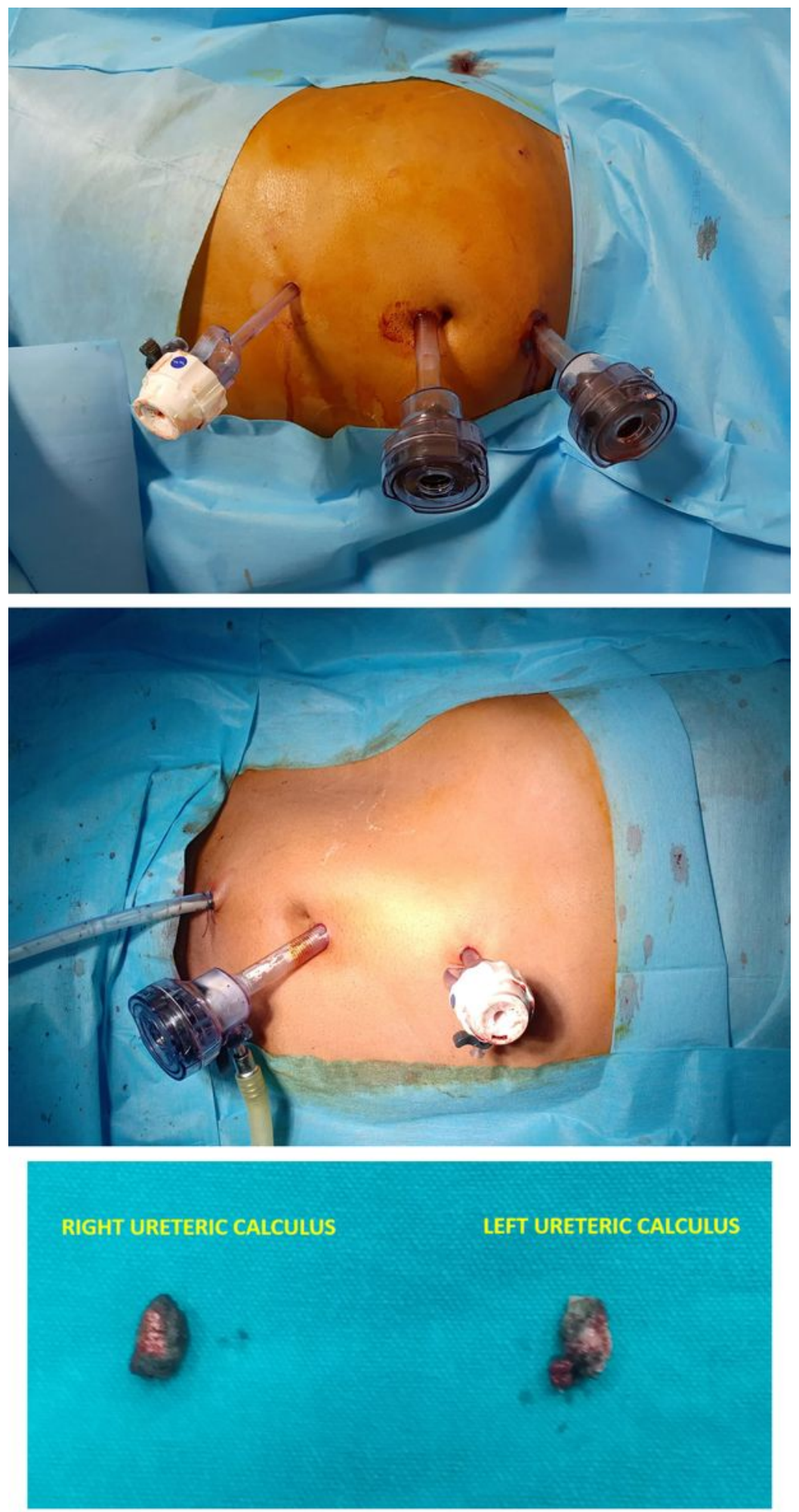

\section{Figure 3}

a: Modified right lateral decubitus position with 3 midline ports for transperitoneal laparoscopic left ureterolithotomy b: Modified left lateral decubitus position with 2 midline ports and drain through the suprapubic port after completion of transperitoneal laparoscopic right ureterolithotomy c: Right and left ureteric calculi after laparoscopic extraction 


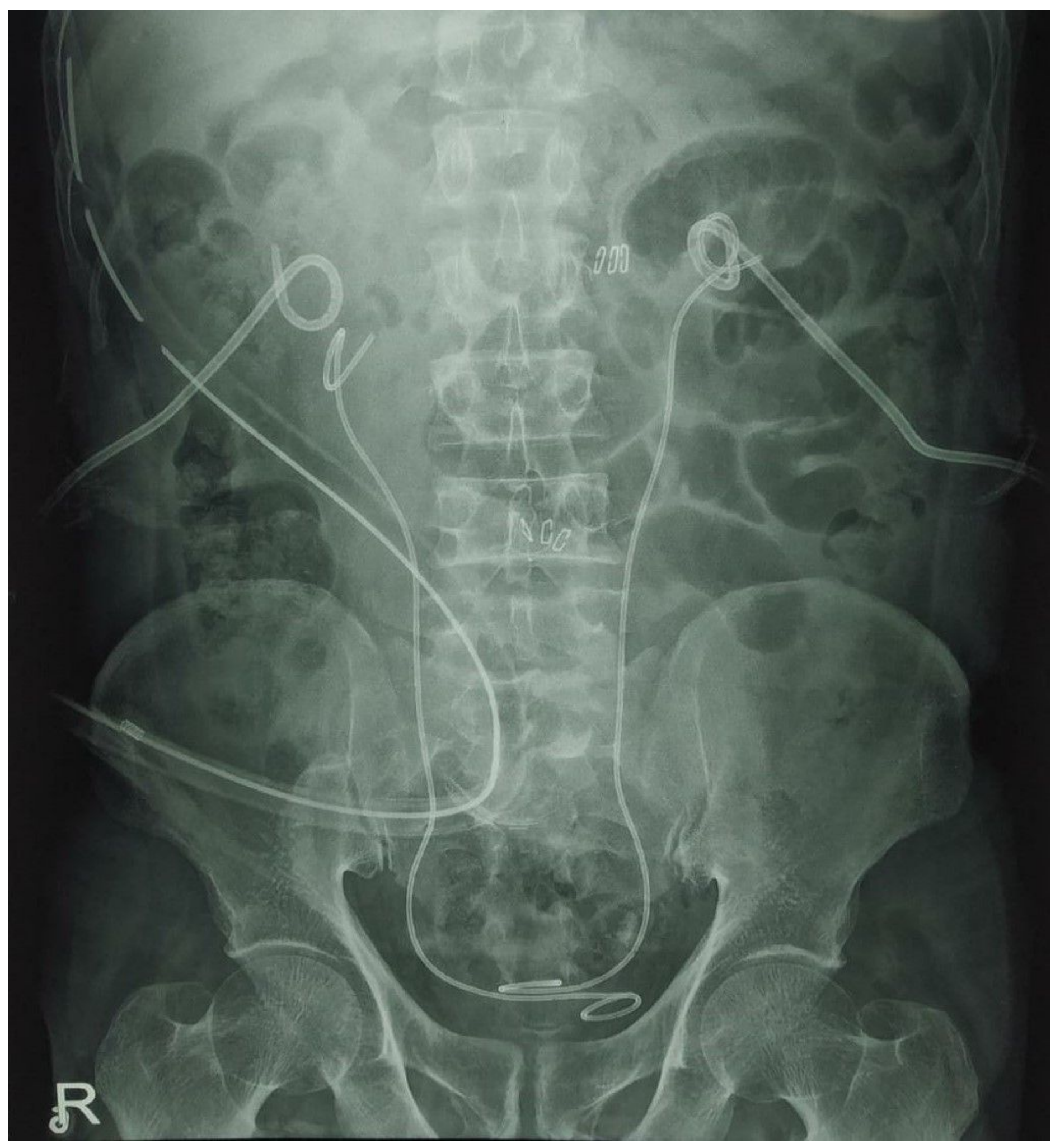

\section{Figure 4}

Satisfactory position of bilateral DJ Stents on X-ray KUB on first postoperative day 


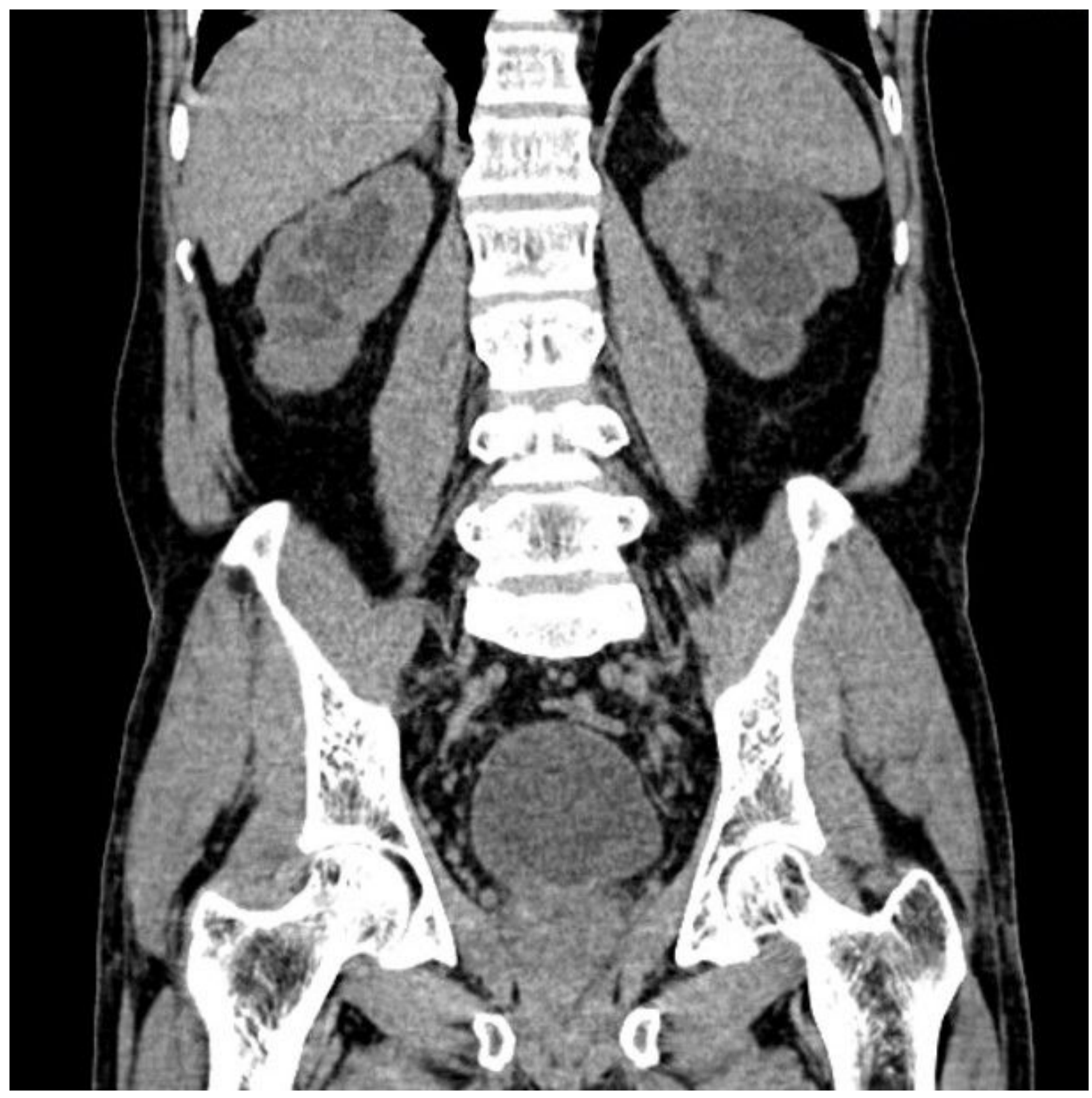

Figure 5

Postoperative NCCT KUB scan after removal of DJ Stents, showing marked improvement of bilateral hydronephrosis and cortical thickness

\section{Supplementary Files}

This is a list of supplementary files associated with this preprint. Click to download.

- CAREChecklist.pdf 